\title{
Effects of the Composition and the Preparation Methods on Oil Sorption Capacity of Recycled Rayon Waste-Kapok Mixtures (RRWK) Sorbent
}

\author{
Chaowalit Senanurakwarkul, Panadda Khongsricharoen, Darathip Pejprom, Supawan Tantayanon, and \\ Sutha Khaodhiar
}

\begin{abstract}
The aim of this study was to investigate the utilization of a recycled rayon waste-kapok mixtures as an oil sorbent for the removal of diesel, motor oil and bunker $C$. The effects of the kapok fibers: rayon fibers ratio and the additional of sodium sulfate on RRWK sorbents properties were investigated through series of oil sorption tests. The ASTM 726-06 method was used to determine the oil sorption capacity of the sorbents under both static and dynamic conditions. The results showed the high sorption capacity of the recycled rayon waste-kapok mixture for difference kinds of oil. Oil, which has a high viscosity, tends to have a higher oil sorption ratio. RRWK sorbents had higher oil sorption capacity than commercial polypropylene. The presence of kapok fibers in RRWK increases the hydrophobicity and oil sorption capacity of the sorbents while the presence of rayon fibers improves the strength of the sorbents. The additional of sodium sulfate during sorbent preparation increases the surface area and pore size of RRWK sorbent and thus improves the oil sorption capacity. It can be concluded that RRWK, which can be produced by utilizing industrial waste, is effective low cost, environmentally friendly oil sorbent with comparable performance to commercial products.
\end{abstract}

Index Terms-Recycled rayon waste-kapok mixtures, oil sorbent, kapok fiber, rayon fibers, polypropylene, oil spill.

\section{INTRODUCTION}

\section{A. Oil in the Environment and Oil Spill Cleanup Method}

Oil is an important energy source and a raw material for the synthesis of various products. Oil can cause environmental pollution during the various stages of its production, storage, transportation, refining, and use. In such cases, oil affects aquatic life, human life, local economies, tourism, and leisure activities because of the coating properties of oil [1]. Oils that are found in contaminated water and land can be heavy

Manuscript received December 6, 2012; revised March 5, 2013. This research was supported by research scholarship " 90th Year Chulalongkorn Scholarship" from the Ratchadapiseksomphote Fund, Chulalongkron University.

Chaowalit Senanurakwarkul is withTechnopreneurship and Innovation Management program, Graduate School, Chulalongkorn University, Bangkok, Thailand (e-mail: Chaowalit.s@student.chula.ac.th).

Panadda Kongsricharoen, Darathip Pejprom and Sutha Khaodhiar are with Department of Environmental Engineering, Chulalongkorn University, Bangkok, Thailand (e-mail: Panadda.k.p@Student.chula.ac.th; Darathip.p@Student.chula.ac.th; Sutha.k@chula.ac.th).

Supawan Tantayanon is with Department of Department of Chemistry, Faculty of Science, Chulalongkorn University, Bangkok, Thailand, Center of Petroleum and Advanced Material, Chulalongkorn University, Bangkok 10330, Thailand, Technopreneurship and Innovation Management, Graduate School, Chulalongkorn University, Bangkok, Thailand. (e-mail: Supawan.t@chula.ac.th). hydrocarbons such as crude oils, and bunker C, and/or light hydrocarbons such as diesel, jet fuel, and gasoline. The major sources of oily waste come from industries such as petroleum refineries and manufacturing [2].

The basic methods for oil spill collection and cleanup are chemical treatment, mechanical treatment and biological treatment. The mechanical method involves the transfer of oil from spill site to temporary storage using oil sorbents or skimmers. Oil sorbents can be classified into organic, inorganic, and synthetic organic products [3]. Good oil sorbents are characterized by high sorption capacity, good buoyancy, adequate oil retention, and reusability [4]. The most common materials used for oil sorbents are synthetic materials such as polypropylene or polyurethane [5]. They have high oleophilic and hydrophobic properties, but they are considered non-biodegradable and are relatively expensive [6]. Thus, many researchers have become interested in studying natural inorganic and organic materials to find substitution materials for oil spill cleanup.

\section{B. Rationale for Using Industrial Waste and Kapok as an Oil Sorbent in the Study}

The rayon industry generates many kinds of wastes including viscose liquid, rayon fibers, and sodium sulfate. Most of these wastes are classified as hazardous waste and must be disposed of in secure landfills. Viscose liquid is one of the waste products from the rejection from the viscose preparation process and maintenance activities such as filtering, sample collecting, process shutdown, and overflow. The viscose liquid contains $\mathrm{NaOH}$, water, and pulp, which are mixed homogeneously by the viscose process. Rayon fiber is produced from wood pulp. The rayon fiber waste is generated from rejection by the drying machine. The rayon fiber is a modified cellulose fiber that is capable of absorbing crude oil [7]. Sodium sulfate, a by-product of the rayon industry, is usually used for the production of hygiene products such as toothpaste and detergent powder. The sodium sulfate waste comes from leakages from packages during transportation and handling. It can be dissolved in water and can be used to increase the porosity of sorbent materials. Sanderson et al., [8] found that sodium sulfate increased the porosity of the cellulose sponge oil sorbent that was made from viscose mixed with cotton and used for testing oil adsorption. Kapok fiber (Ceiba pentandra (L.) Gaertn.) is an agricultural product which has been used as an oil sorbent material. Kapok has a high tube structure with large lumen. The kapok fibers are fluffy, yellowish-brown, lightweight, inelastic, and brittle. It is composed of $64 \%$ cellulose and 13\% lignin. Beside these constituents, it also 
contains waxy material on the fiber surface, which makes its exhibit water repellent properties [9].

In this study, the wastes generated from the manufacture of rayon, including viscose liquid, rayon fibers, and sodium sulfate, were blended with kapok at different $\%$ weight ratio to develop the materials that were qualified as an oil sorbents. These sorbents were then evaluated for oil sorption efficiency and then the results were compared with synthetic oil sorbents (polypropylene) following the ASTM F726-06 Standard Test Method for Sorbent Performance of Adsorbent[10].

\section{MATERIALS AND METHOD}

\section{A. Oil Sorbent Material Made of Recycled Rayon Waste-Kapok Mixtures (RRWK)}

In this study, for each type of prepared sorbent, 100:0, $75: 25,50: 50,25: 75,0: 100(\% \mathrm{wt})$ by 10 grams of kapok fibers: rayon fibers with $14: 86$ (\%wt) by 187.5 grams of viscose liquid mixtures: water, were thoroughly mixed. After that, 0 or 75 grams of sodium sulfate salt (size 150 microns) were added to the mixture and blended by mixer for 30 seconds. The mixed material was put into a container and washed with $10 \%(\mathrm{v} / \mathrm{v})$ sulfuric acid for 30 minutes. Next, the prepared materials were rinse with hot water $98^{\circ} \mathrm{C}$ for 1 minute to remove sodium sulfate, washed with water to remove any soluble constituents, and then dried in a drying machine at $60^{\circ} \mathrm{C}$ for 24 hours. The prepared sorbent materials were lightweight fibers with a brown and/or white color.

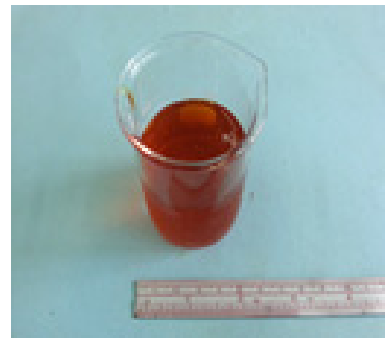

(a)

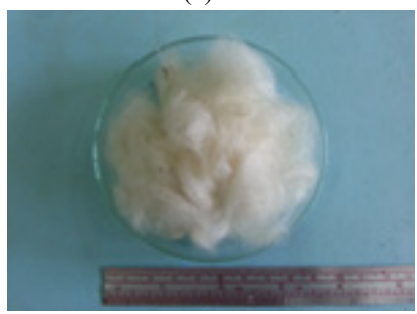

(c)

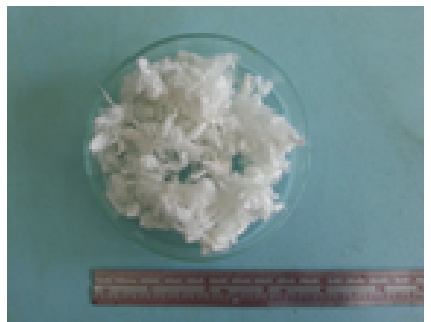

(b)

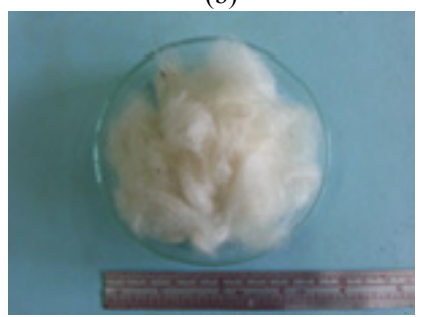

(d)
Fig. 1. The materials used for RRWK sorbent. (a) Viscose liquid, (b) Rayon fiber waste, (c) Kapok fibers, (d) Sodium sulfate waste

\section{B. Characterization of Sorbent Materials}

Physical characteristics and diameter of the kapok fiber, rayon fiber, polypropylene and RRWK were analyzed using a Scanning Electron Microscope (SEM, JEOL type JSM-5410LV). The moisture of materials content of the materials was analyzed by hot air oven method.

\section{Property of Oil}

Three types of oil, diesel, motor oil SAE 20W 50 and bunker $\mathrm{C}$, were evaluated through oil sorption in this study. The diesel, motor oil and bunker $\mathrm{c}$ were purchased from PTT
(Thailand) Co., Ltd. Diesel oil is representative of low-viscosity oils such as gasoline and kerosene. Motor oil is representative of medium-viscosity oils such as crude oil. Bunker $\mathrm{C}$ oil is representative of heavy-viscosity oils. Viscosity of each type of oil was measured using a Viscometer (Brookfield / LVDV III). The density and viscosity of the investigated oils are summarized in Table I

\begin{tabular}{ccc} 
TABLE I: PHYSICAL PrOPERTIES OF THE INVESTIGATED OILS AT $25^{\circ} \mathrm{C}$ \\
\hline Type of oil & Density $\left(\mathrm{kg} / \mathrm{m}^{3}\right)^{*}$ & Viscosity $(\mathrm{cp})$ \\
\hline Diesel oil & 0.85 & 26 \\
Motor oil & 0.88 & 323 \\
Bunker C & 0.96 & 2265 \\
\hline * Obtained from the product specifications provided by PTT
\end{tabular}

\section{Dynamic Water-Sorption Test}

A water take-up study was conducted to determine the oleophillic properties of the sorbents under dynamic conditions. Approximately 5 grams of different sorbents were weighed, and then placed in a 4-liter jar that was half-filled with water. The jar was sealed and shaken at 150 rpm for 15 minutes. After that, the condition of the sorbents and water was observed. If $10 \%$ or more of the sorbents had sunk, then the sorbent was considered to have failed this test. The contents in the jar were strained through a mesh basket to catch the sorbents, and weighted after a 30 seconds drain period. The water sorption capacity ( $\mathrm{g}$ of water/g of sorbent) was calculated from equation 1.

$$
\text { Water sorption capacity }=\mathrm{S}_{\mathrm{w}} / \mathrm{S}_{\mathrm{o}}
$$

where $S_{o}$ is the initial dry sorbent weight, $S_{w t}$ is the weight of the sorbent sample at the end of the water take up test, and $S_{w}$, $\left(\mathrm{S}_{\mathrm{wt}}-\mathrm{S}_{\mathrm{o}}\right)$ is the net water sorbed.

\section{E. Oil-Sorption Study}

The procedure for determining oil sorption capacity generally followed the ASTM F 726-06 method. Each of loose-form RRWK and PP sorbent was placed inside a wire-mesh basket and immersed inside an oil bath until it reached the test time limit as detailed below.

Short test (15 minutes) under static conditions: 50 grams of diesel, motor oil and bunker $\mathrm{C}$ were poured into a beaker. Thereafter, 5 grams of RRWK were put in a screen and placed on the oil surface. After 15 minutes, the material was removed using forceps and drained for 30 seconds ( 2 minutes drain time was used for bunker C).

Long test (24 hours) under static condition: $50 \mathrm{~g}$ of diesel, motor oil and bunker $\mathrm{C}$ were poured into a beaker. Thereafter, 5 grams of RRWK were put in a screen and placed on the oil surface. After 24 hours, the material was removed using forceps and drained for 30 seconds ( 2 minutes drain time was used for bunker c).

The oil-sorbed material was weighed. The oil sorption capacity was determined using the following equation.

$$
q=S_{t}-S_{0} / S_{0}
$$

where $q$ is the sorption capacity ( $\mathrm{g}$ of oil/g of sorbent), $S_{\mathrm{t}}$ is the total mass of the sorbed samples $(\mathrm{g})$, and $S_{0}$ is the initial mass of the sorbed materials. 


\section{RESUlTS AND DisCUSSION}

\section{A. Characteristics of the Materials}

Table II compares the characteristics of materials including kapok fiber, rayon fiber, and polypropylene. There are several factors used in determining the physical characteristics of oil sorbent material such as structure of fiber, moisture content, material strength, color, sorption and buoyancy.

TABLE II: CHARACTERISTIC PROPERTIES OF MATERIAL

\begin{tabular}{|c|c|c|c|}
\hline Characteristics & Kapok fiber & Rayon fiber & Polypropylene \\
\hline Diameter of fiber $(\mu \mathrm{m})$ & 21.5 & 9.37 & 27.2 \\
\hline Moisture (\%) & 8.25 & 5.67 & 1.56 \\
\hline Surface & Smooth & Rough & Rough \\
\hline Tensile strength(MPa) & $93.3^{\mathrm{a}}$ & $637^{\mathrm{b}}$ & $300^{\mathrm{c}}$ \\
\hline Density $\left(\mathrm{g} / \mathrm{cm}^{3}\right)$ & $1.3^{\mathrm{d}}$ & $1.49^{\mathrm{b}}$ & $0.92^{\mathrm{e}}$ \\
\hline Specific gravity & $0.055^{\mathrm{a}}$ & $1.52^{\mathrm{b}}$ & $0.91^{\mathrm{e}}$ \\
\hline Buoyancy ( water ) & Float & Sink & Float \\
\hline Color & Yellow-brown & White & White \\
\hline Sorption & $\begin{array}{c}\text { Hydrophobic / } \\
\text { Oleophilic }\end{array}$ & Hydrophilic & $\begin{array}{c}\text { Hydrophobic / } \\
\text { Oleophilic }\end{array}$ \\
\hline
\end{tabular}

* a [11], b [12], c [13], d [14], e [15]

The kapok fiber has a smooth surface with hollow microstructure (or lumen) as shown in the SEM images in Fig. 2(a) while rayon fiber and polypropylene has a rough surface without internal structure as shown in the SEM image in Fig. 2(b) and 2(c). Kapok fiber and polypropylene are hydrophobic and oleophilic, which have high rate of oil sorption and good buoyancy [16]-[17]. On the other hand, rayon fiber is hydrophilic and has high affinity for water and bad buoyancy. In this study, the kapok fibers in RRWK sorbents provide the hydrophobic surface for oil sorption while rayon fibers in the mixtures provide the strength of the sorbent. The polypropylene is oil sorbent in commercial market, which was used to compare with RRWK sorbents for the performance of oil sorption.

\section{B. Water Sorption Capacity}

Fig. 3 shows that the highest water sorption capacity was $40.65 \mathrm{~g}$ of water/g of sorbent from 100:0(\% wt) kapok fibers: rayon fibers, Meanwhile, the ratio of 0:100(\% wt) kapok fibers: rayon fibers had failed for testing due to the sample sunk under the water. The water sorption capacities of the RRWK sorbents were higher than the PP oil sorbent (1.52 g of water/g of sorbent) due to the presence of rayon fibers in the sorbents.

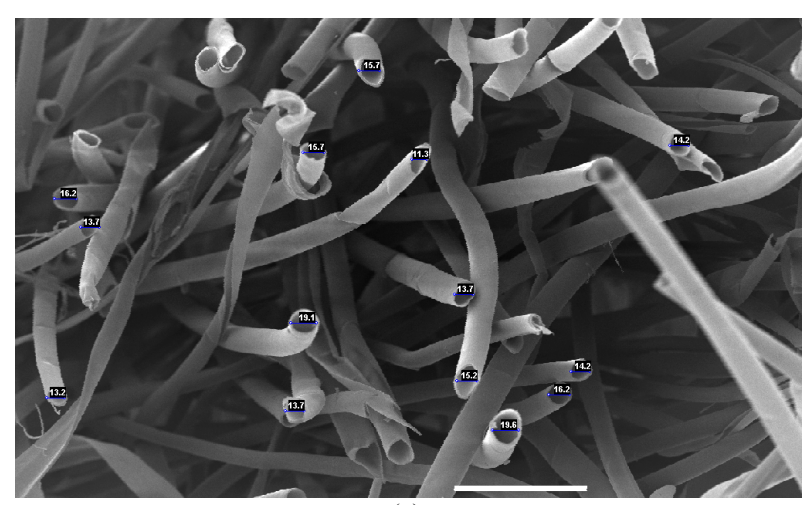

(a)

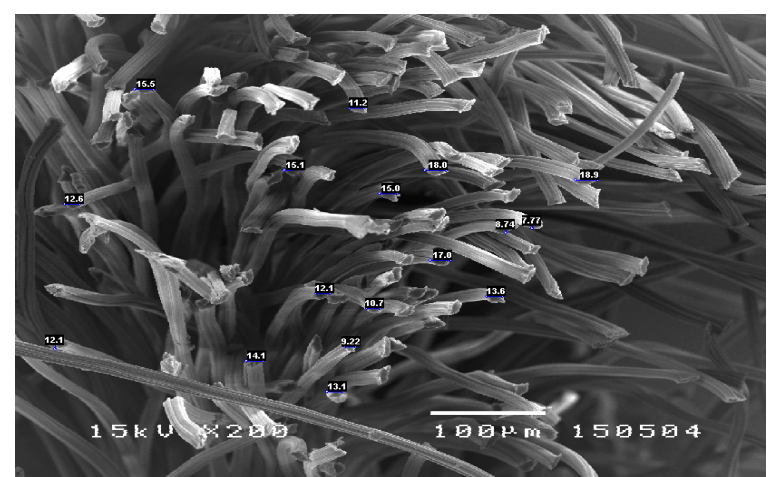

(b)

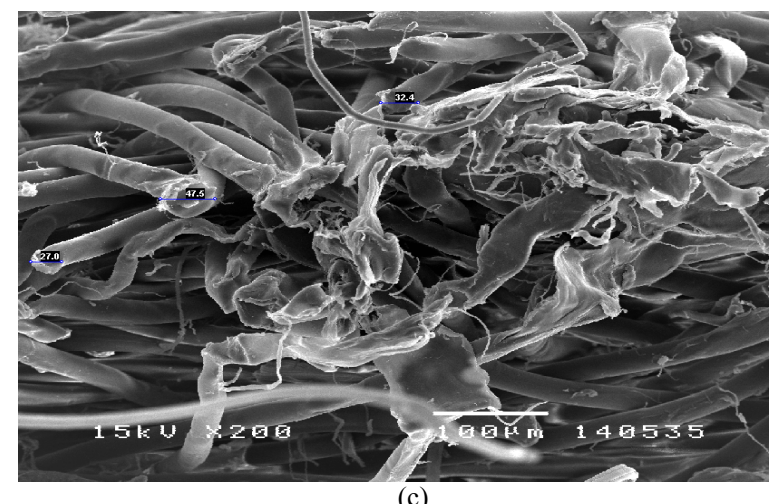

Fig. 2. SEM images of materials, (a) Kapok fibers, (b) Rayon fibers, (c) Polypropylene

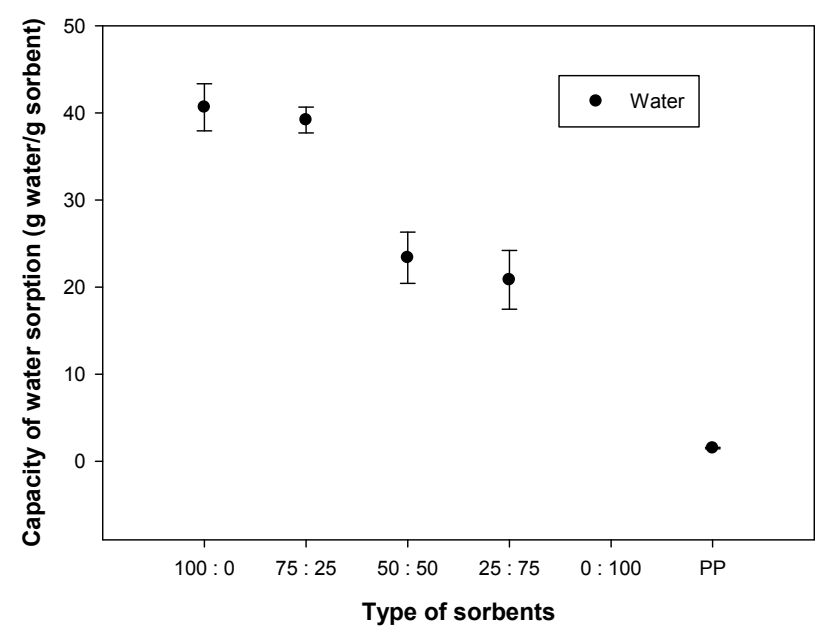

Fig. 3. Kapok fibers: rayon fibers ratio (\% wt) on water sorption capacity ( $\mathrm{g}$ of water/g of sorbent) with sodium sulfate addition and polypropylene (PP).

\section{Oil sorption Capacity}

The sorption capacities of RRWK sorbents for diesel oil, motor oil and bunker $\mathrm{C}$ under static conditions after 15 minutes and 24 hours are presented in the Fig. 4. Fig. $4 \mathrm{a}$ and $4 \mathrm{~b}$ show that for RRWK sorbents, the kapok fibers: rayon fibers ratio of 100:0 (\%wt) has the highest sorption capacity for all types of oil. Oil sorption capacity of RRWK decreases with increasing amount of rayon fibers in the mixture. The lowest oil sorption capacity was observed with $0: 100(\% \mathrm{wt})$ kapok fibers: rayon fibers. The sorption results the tested oils after 15 minutes and 24 hours were not significantly different because of its ability to absorb oil up until its maximum limits within a very short time. The sorption of diesel, motor and bunker c oils by the RRWK sorbents were different mainly because of the differences in oil viscosity. Wei et al., [18] 
reported that oil with higher viscosity tends to have a higher initial sorption ratio. As predicted therefore, bunker c, which has the highest viscosity among the test oils, showed much greater sorption by RRWK sorbents.
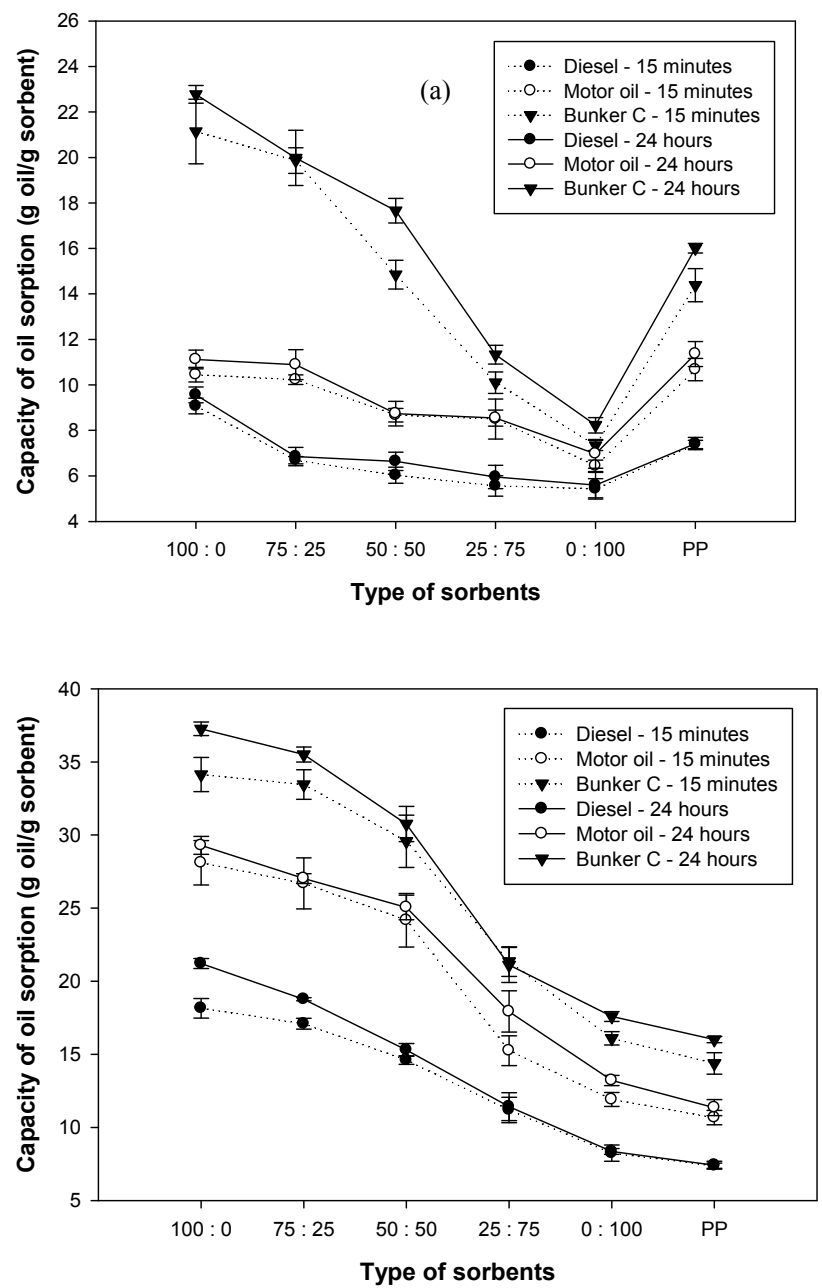

Fig. 4. Capacity of oil sorption from kapok fibers: rayon fibers ratio (\%wt) and PP for diesel, motor oil and bunker c (a) short test and long test, (b) short test and long test with sodium sulfate addition

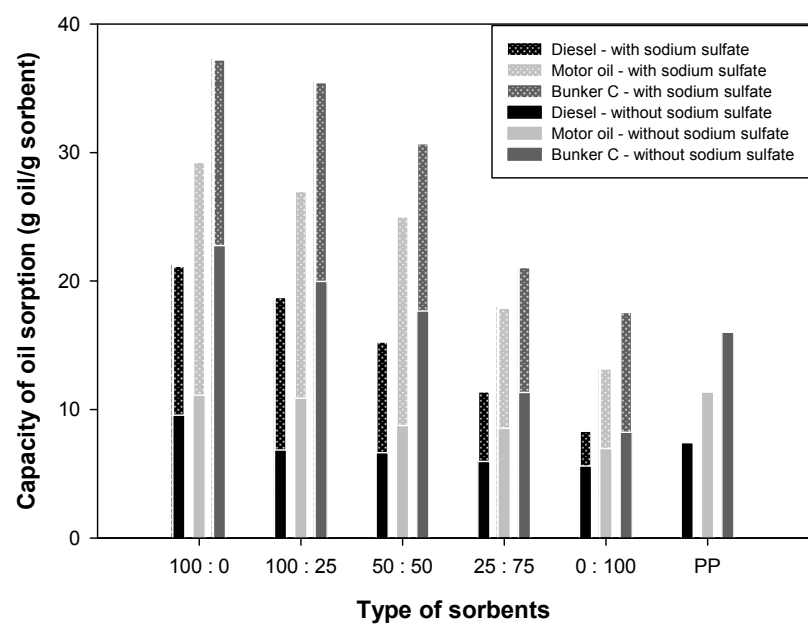

Fig. 5. Capacity of oil sorption ( 24 hours) from kapok fibers: rayon fibers ratio $(\% \mathrm{wt})$ ( with sodium sulfate and without sodium sulfate) and PP

Comparison between the RRWK sorbents with sodium sulfate addition during sorbent preparation and the RRWK sorbents without sodium sulfate after oil sorption at 24 hours in Fig. 5 shows that the oils sorption capacity of the RRWK sorbents with sodium sulfate were higher than that of RRWK sorbents without sodium sulfate. The addition of sodium sulfate into RRWK sorbents increase oil sorption capacity because sodium sulfate controlled the coagulation of the pore walls, which made the sorbent of the capillary surface larger [19]. The results shown that RRWK sorbent with sodium sulfate had true density of $1.04 \mathrm{~g} / \mathrm{cm} 3$ while RRWK sorbent without sodium sulfate had true density of $1.30 \mathrm{~g} / \mathrm{cm} 3$ in Fig. 6. It can be indicated that RRWK sorbent with sodium sulfate had lesser density than that of RRWK sorbent without sodium sulfate. The additional of sodium sulfate affects the density of RRWK sorbent, which may increases surface area and pore size of RRWK for oil sorption. The surface area and pore size are important factors for sorbent material since they affect the rate at which a fluid flows into or thorough a capillary network [20]. RRWK sorbents with sodium sulfate showed a higher sorption capacity than PP. It can be indicated that RRWK sorbent is an effective of oil sorption with comparable performance to commercial products.

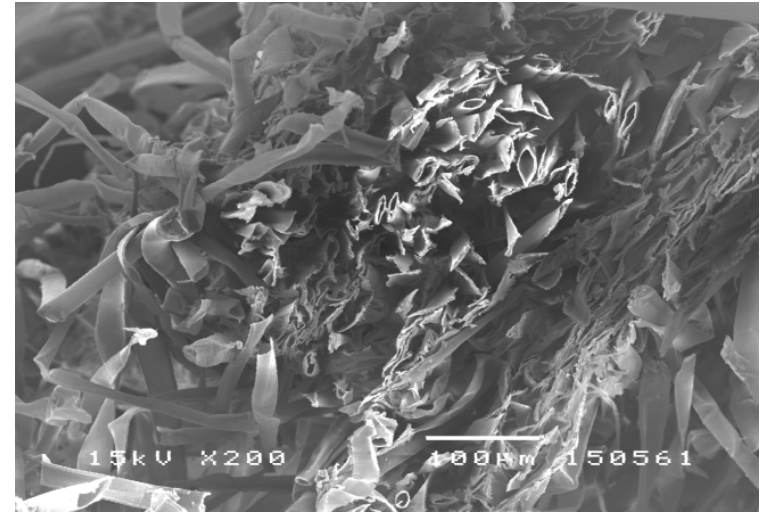

(a)

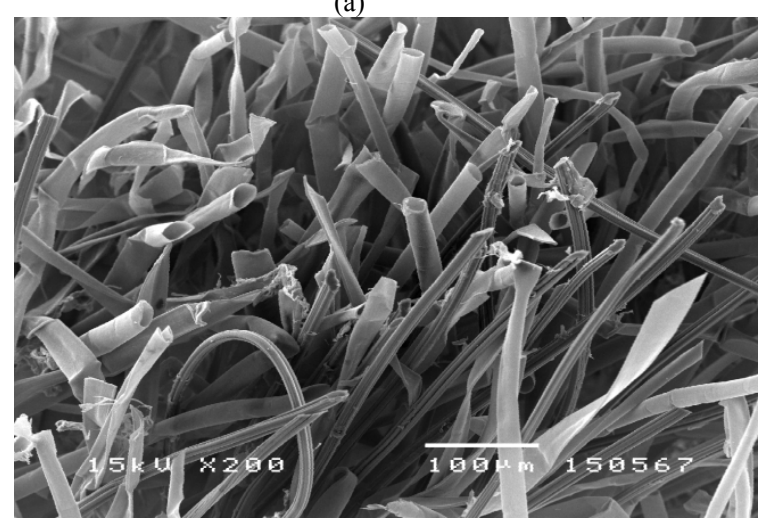

(b)

Fig. 6. SEM images of RRWK sorbents, (a) Kapok fibers: rayon fibers ratio 50:50(\%wt) (b) Kapok fibers: rayon fibers ratio 50:50(\%wt) with sodium sulfate

\section{CONCLUSION}

A recycled rayon waste-kapok mixtures (RRWK) can be used for the sorption of different types of oil (diesel, motor oil and bunker C) under static condition. Oil with a higher viscosity tends to have a higher oil sorption. The mixture of 100:0(\% wt) kapok fibers: rayon fibers sodium sulfate was the most effective approach for oil sorption. It means that the oil sorption capacity increased with an increasing amount of kapok fibers. The additional of sodium sulfate into RRWK 
increases the efficiency of oil sorption, which affects density of RRWK sorbent. RRWK sorbent with sodium sulfate displayed a capacity for oil and water sorption that was higher than polypropylene. Therefore, RRWK sorbent has the potential to be developed into a commercial product.

\section{ACKNOWLEDGMENT}

The authors thank Thai Rayon Public Company (Thailand) for supporting these rayon industrial wastes.

\section{REFERENCES}

[1] M. Hussein, A. A. Amer, and I. I. Sawsan, "Oil spill sorption using carbonized pith bagasse: trial for practical application," Int. J .Environ. Sci. Tech., vol. 5, no. 2, pp. 233-242, Mar. 2007.

[2] M. Quemeneur, and Y. Marty, "Fatty acids and sterols in domestic wastewater," Water Research, vol. 28, no. 5, pp. 1217-1226, July 1994.

[3] T. T. Lim, and X. Huang, "Evaluation of kapok (Ceiba pentandra (L.) Gaertn.) as a natural hollow hydrophobic-oleophilic fibrous sorbent for oil spill cleanup," Chemosphere, vol. 66, no. 5, pp. 955-963, Jan. 2007.

[4] M. Radetic, V. Ilic, D. Radojevic, R. Miladinovic, D. Jocic, and R. Jovancic, "Efficiency of recycled wool-based nonwoven material for the removal of oils from water," Chemosphere, vol. 70, pp. 525-530, Jan. 2008.

[5] C. H. Teas, S. Kalligeros, F. Zanikos, S. Stournas, E. Lois, and G. Anastopulos, "Investigation of the effectiveness of absorbent material in oil spill clean up," Desalination, vol. 140, pp. 259-264, Nov. 2001.

[6] H.-M. Choi, and R. M. Cloud, "Natural sorbents in oil spill cleanup," Environmental Science \& Technology, vol. 26, pp. 772-776, April 1992.

[7] R. F. Johnson, and T. G. Manjrekar, "Removal of oil from water surfaces by sorption on unstructured fibers," Environmental Science \& Technology, vol. 7, pp. 439-443, May 1973.

[8] S. Alan, D. Rod., M. Fang, and H. John, "Cross-linked cellulose sponge," U.S. Patent 5690096, Nov. 25, 1997.

[9] R. S. Rengasamy, D. Das, and C. Karan, "Study of oil sorption behavior of filled and structured fiber assemblies made from polypropylene, kapok and milkweed fibers," Journal of Hazardous Materials, vol.186, pp. 526-553, Feb. 2011.

[10] Standard test method of sorbent performance of adsorbents, ASTM Standard F726-06 - 2008.

[11] L. Y. Mwaikambo, "Review of the history, properties and application of plant fibres," African Journal of Science and Technology, vol. 7, no. 2, pp. 120 - 133, Dec. 2006.

[12] Annual Report, Thai Rayon Public Co., Bangkok, TH, 2009.

[13] B. I. Naayudhya, "Compressive and splitting tensile strength of autoclaved aerated concrete (AAC) containing perlite aggregate and polypropylene fiber subjected to high temperatures," Songklanakarin J. Sci. Technol, vol 33, no. 5, pp. 555-563, Oct. 2011.

[14] M. A. Abdullah, U. R. Anisa, and Z. Man, "Physicochemical and sorption characteristics of Malaysian Ceiba pentandra (L.) Gaertm. As a natural oil sorbent," Journal of Hazardous Material, Dec. 2009.
[15] B. Schmenk, R Miez-Meyer, M. Steffens, B. Wulfhorst, and G. Gleixner, "Polypropylene fiber table," Chemical Fibers International, vol. 50, no. 3, pp. 233-253, May 2000.

[16] T. T. Lim, and X. Huang, Evaluation of hydrophobicity / oleophilicity of kapok and its performance in oily water filtration: comparison of raw and solvent- treated fibers, Industrial Crops and Product, vol. 26 pp. 125-134, Aug. 2007.

[17] X. Huang, and T. T. Lim, Performance and mechanism of hydrophobic-oleophilic kapok filter for oil/water separation, Desalination, vol. 190, pp. 295-307, April 2006.

[18] Q. F. Wei, R. R. Mather, A. F. Fotheringham, and R. D. Yang, "Evaluation of nonwoven polypropylene oil sorbents in marine oil-spill recovery," Marine Pollution Bulletin, vol. 46, pp. 780-783, June 2003.

[19] R. O. Osborn, “Cellulosic sponge process," U.S. Patent 2,836,503, Serial No. 417,961, Mar. 1954.

[20] P. K. Chatterjee and B. S. Gupta, Absorbent Technology, 1st ed. Amsterdam: Elsevier B.V., 2002, ch. 2, pp. 78-79.

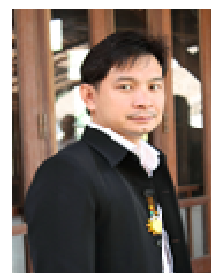

Chaowalit Senanurakwarkul received his B.Sc. in occupational health and safety from Faculty of Public Health, Mahidol University, Thailand, his M.Sc. industrial hygiene and safety from Faculty of Public Health, Mahidol University, Thailand. He is currently Ph.D. student in Technopreneurship and Innovation Management program , Chulalongkorn University, Thailand. His research interest focuses on innovative oil sorbent for oil removal.

Panadda Kongsricharoen received her B.Sc. in chemistry from faculty of science, Prince of Songkla University, Thailand. She is currently M.Sc. student in environmental engineering program, Chulalongkorn University, Thailand. Her research interest focuses on the development of oil sorbent from kapok fiber and rayon industrial waste.

Darathip Pejprom received her B.Sc. in environmental science from faculty of science and technology, Thamasat University, Thailand, She is currently M.Sc. student in environmental engineering program, Chulalongkorn University, Thailand. Her research interest focuses on the adsorption of BTEX by kapok fiber and rayon industrial waste.

Sutha Khaodhiar received his B.E. in environmental engineering from Chulalongkorn University, Thailand, and his M.Sc. and Ph.D. in environmental engineering from Oregon State University. He is currently an associate professor in the Department of Environmental Engineering, Chulalongkorn University. His research interest focuses on complex reactions of contaminants in aqueous environments.

Supawan Tatayanon received her B.Sc. honour (Chemistry) from Chulalongkorn University, Thailand, and her M.Sc. (Organic Chemistry), Mahidol University, Thailand and Ph.D. in (Organic Chemistry), Worcester Polytechnic Institute, USA. She is currently an associate professor in the Department of Chemistry, Faculty of Science, Chulalongkorn University. Her research interest focuses on Enhanced Toughening Polypropylene with Reclaimed Tire-Rubber 